\title{
Postoperative complications and association with outcomes in pediatric cardiac surgery
}

\author{
Hemant S. Agarwal, MBBS, FAAP, ${ }^{a}$ Karen B. Wolfram, RN, ${ }^{a}$ Benjamin R. Saville, PhD, ${ }^{b}$ \\ Brian S. Donahue, MD, PhD, ${ }^{\mathrm{a}, \mathrm{c}}$ and David P. Bichell, $\mathrm{MD}^{\mathrm{d}}$
}

\begin{abstract}
Objective: Our primary aim was to study postoperative complications in pediatric cardiac surgery patients and their association with cardiopulmonary bypass (CPB) use. The secondary aim was to evaluate the association of postoperative complications with established outcome measures.
\end{abstract}

\begin{abstract}
Methods: A single-institution retrospective observational study was undertaken of consecutive pediatric cardiac surgery patients during a 1-year period. Five cardiac and 15 extracardiac complications were studied. CPB use, CPB parameters, demographics, and Risk Adjusted Classification for Congenital Heart Surgery (RACHS-1) levels were evaluated as risk factors for complications. Outcomes, including mechanical ventilation duration, pediatric cardiac intensive care unit stay, hospital stay, and mortality were studied.
\end{abstract}

Results: A total of 325 patients were studied: 271 with CPB and 54 without CPB. Of the 325 patients, 141 (43\%) had $\geq 1$ complication ( $95 \%$ confidence interval, 38\%-49\%). Of the 325 patients, $82(25 \%)$ developed cardiac and $120(37 \%)$ developed extracardiac complications. The evidence from logistic regression analysis was insufficient to suggest a relationship between CPB support and the incidence of cardiac or extracardiac complications after adjusting for age, gender, previous sternotomy, and RACHS-1 levels. For patients receiving $\mathrm{CPB}$, longer $\mathrm{CPB}$ times, higher RACHS-1 levels, and a lower temperature with CPB were associated with a greater number of cardiac complications $(P<.01)$. Longer CPB times and higher RACHS-1 levels were associated with a greater number of extracardiac complications $(P=.006)$. Postoperative complications were significantly associated with an increased mechanical ventilation duration, pediatric cardiac intensive care unit stay, and hospital stay and mortality $(P<.01)$.

Conclusions: Postoperative complications occurred in $43 \%$ of pediatric cardiac surgeries performed both with and without $\mathrm{CPB}$. The complications were associated with longer mechanical ventilation and pediatric cardiac intensive care unit and hospital stays, and increased mortality. (J Thorac Cardiovasc Surg 2014;148:609-16)

\section{Supplemental material is available online.}

National benchmark data have revealed that overall mortality after congenital heart surgery is $<4 \%$ at most institutions. ${ }^{1-3}$ The complications and the factors contributing to these complications are more challenging targets to measure and interinstitutional comparisons less easily made. Postoperative cardiac and extracardiac complications in

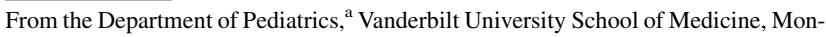
roe Carell Jr, Children's Hospital at Vanderbilt, Nashville, Tenn; Department of Biostatistics, ${ }^{\text {b }}$ Vanderbilt University Medical Center, Nashville, Tenn; Division of Pediatric Cardiac Anesthesia, ${ }^{\mathrm{c}}$ Department of Anesthesia, Vanderbilt University Medical Center, Nashville, Tenn; and Department of Cardiothoracic Surgery, ${ }^{\mathrm{d}}$ Monroe Carell Jr Children's Hospital at Vanderbilt, Nashville, Tenn.

Disclosures: Authors have nothing to disclose with regard to commercial support.

Received for publication June 18, 2013; revisions received Aug 20, 2013; accepted for publication Oct 11, 2013; available ahead of print Nov 25, 2013.

Address for reprints: Hemant S. Agarwal, MBBS, FAAP, Department of Pediatrics, Vanderbilt University School of Medicine, Monroe Carell Jr, Children's Hospital at Vanderbilt, 5121 Doctor's Office Tower, 2200 Children's Way, Nashville, TN 37232-9075 (E-mail: Hemant.Agarwal@ Vanderbilt.edu).

$0022-5223 / \$ 36.00$

Copyright (C) 2014 by The American Association for Thoracic Surgery http://dx.doi.org/10.1016/j.jtcvs.2013.10.031
}

pediatric cardiac surgery have been inconsistently reported but contribute importantly to mortality, hospital stay, cost, and quality of life after pediatric cardiac surgery. ${ }^{4-6}$ Focused on incentivizing cost-effective care, payers and regulators have also had an increasing interest in measuring postoperative complications. ${ }^{7}$ The Centers for Medicare and Medicaid Services have begun withholding payment for certain complications, such as postoperative sternal wound infections. ${ }^{7}$ Plans have been expanding to link provider remuneration to complication rates as the Medicare revisions have continued to unfold.

"Failure to rescue" concepts have been applied to pediatric cardiac surgery to demonstrate that institutions with the best outcomes might not have fewer complications but, rather, have the systems in place to recognize and correct complications before deleterious outcomes ensue. ${ }^{5}$ Two patients with the same technically excellent operation, delivered to 2 different intensive care units, can have vastly different courses and outcomes, depending on the recognition, prevention, and treatment strategies for the same complications at the respective institutions. The duration of mechanical ventilation, postoperative length of stay, and hospital stay can be influenced by individual and institutional practices, complicating interinstitutional comparisons. ${ }^{2,8,9}$ Optimal outcomes 


\section{Abbreviations and Acronyms \\ $\mathrm{CPB}=$ cardiopulmonary bypass \\ PCICU = pediatric cardiac intensive care unit \\ RACHS-1 = Risk Adjusted Classification for \\ Congenital Heart Surgery, version 1}

depend on the contribution of multiple disciplines of care to the journey of a patient from office to operating room to intensive care unit to floor, and weaknesses in any of those areas can subvert the successful work done in another. The importance of improving the accurate recognition, documentation, and standardization of accounting for complications is relevant to the length of treatment, cost, and clinical outcome. Few studies have reported an association between complications and outcome measures such as the duration of mechanical ventilation, postoperative length of stay, and mortality. ${ }^{4,5}$ The primary purpose of our study was to evaluate the cardiac and extracardiac complications in the postoperative period and to study the association of cardiopulmonary bypass (CPB) use and the occurrence of these complications. Our secondary purpose was to study the association of complications with outcome measures such as the duration of mechanical ventilation, postoperative length of PCICU and hospital stay, and mortality.

\section{METHODS}

The present retrospective study was conducted at the Pediatric Heart Institute at Monroe Carell Jr Children's Hospital at Vanderbilt University and was approved by the Vanderbilt institutional review board. All pediatric patients (age 0-18 years) who had undergone cardiac surgery during 2008 were included. Patients undergoing neonatal patent ductus arteriosus ligation or reoperation during the same hospital admission and patients not admitted to the PCICU for postoperative care were excluded from the present study.

Postoperative complications were defined in accordance with the consensus definitions of the Multi-Societal Database Committee for Pediatric and Congenital Heart Disease (see Appendix Table E1). Complications were considered present if any 1 of the 20 predefined postoperative complications occurred in the PCICU. They were categorized into 1 of the 8 body systems: cardiac, neurologic, pulmonary, gastrointestinal, renal, infectious, endocrine, and hematologic. ${ }^{10,11}$ Of the 20 complications, 5 were related to the cardiovascular system and 15 were related to the 7 extracardiac systems and evaluated for every patient studied. For much of the statistical analysis, the complications were divided into cardiac and extracardiac. Additionally, the length of mechanical ventilation, PCICU stay, and hospital stay and mortality were evaluated. Mortality was defined as death within the first 30 days after surgery or before hospital discharge. ${ }^{3}$ We also evaluated the survival of these patients 1 year after their cardiac surgery.

The potential risk factors for an increased number of postoperative complications in the present study included the use of CPB support, CPB time, crossclamp time, lowest core temperature during $\mathrm{CPB}$, lowest hematocrit during $\mathrm{CPB}$, total heparin dose, and post- $\mathrm{CPB}$ core body temperature. The heparin dosage evaluated in our study corresponded to the heparin administered to the patient during $\mathrm{CPB}$ ( $\mathrm{CPB}$ prime and during $\mathrm{CPB}$ period) and did not include any postoperative usage for patency of indwelling catheters. Other potential risk factors evaluated included the complexity of the cardiac surgery according to the Risk Adjusted Classification for Congenital Heart Surgery, version 1 (RACHS-1), ${ }^{12}$ single- or 2-ventricle physiology, previous sternotomy, and demographics, including age, weight, and gender.

The clinical data and outcomes were collected separately by a critical care clinical nurse educator and a critical care physician from the electronic medical records and patient charts. The data from both sources were compared for any disparities. Any inclusion or exclusion of any complication was reviewed if disagreement was found between the 2 sources. The data collection was also matched with the cardiac surgery division surgical data, which had been collected separately.

Continuous variables are presented as median values and interquartile ranges and categorical variables as numbers and percentages. For univariate analysis, the Wilcoxon rank sum test was used to compare continuous variables and Pearson's chi-square test to compare categorical variables. Proportional odds logistic regression analysis was undertaken to analyze the risk factors for an increased number of cardiac and extracardiac complications. Linear regression analysis was used to regress the length of mechanical ventilation and length of hospital stay on postoperative complications, adjusting for relevant confounders. A log transformation was used for the length of mechanical ventilation to satisfy normality assumptions. Proportional odds logistic regression analysis and logistic regression analysis were used to analyze the length of PCICU stay and mortality with complications, respectively, adjusting for relevant confounders.

\section{RESULTS}

A total of 405 pediatric cardiac surgeries were performed within 1 calendar year, and 325 patients met the inclusion criteria for our study. Of the 80 excluded patients, 26 neonates underwent patent ductus arteriosus ligation, 18 patients underwent reoperation during the same hospital stay, and 16 patients were admitted directly to the cardiology floor (10 patients underwent pacemaker placement or revision, 2 patients underwent pericardial window creation, 3 patients underwent vascular ring resection, and 1 patient underwent sternal wire removal).

The demographics and risk factors evaluated for $325 \mathrm{pa}-$ tients are listed in Table 1. Of the 325 surgeries, 271 (83\%) were performed with CPB support and $54(17 \%)$ without CPB support. Univariate analysis revealed that patients undergoing surgery without CPB support were significantly younger, weighed less, and had undergone fewer previous surgeries compared with those undergoing surgery with CPB support (Table 1). All 271 surgeries with CPB were performed without the use of deep hypothermic circulatory arrest.

Of the 325 patients studied, 141 (43\%; 95\% confidence interval [CI], 38\%-49\%) experienced $\geq 1$ complication. Of the 271 patients who received CPB support, 126 (46\%; $95 \%$ CI, $40 \%-53 \%$ ) developed $\geq 1$ complication. Of the 54 patients who underwent surgery without CPB support, $15(28 \% ; 95 \%$ CI, $16 \%-42 \%)$ had $\geq 1$ postoperative complication. The descriptive statistics for the 20 postoperative complications evaluated in our study are listed in Table 2, stratified by CPB support. Evaluation of the interaction between cardiac and extracardiac complications revealed that all 37 renal complications, all 5 complications 
TABLE 1. Demographics and risk factors of study population

\begin{tabular}{lccc}
\hline & \multicolumn{2}{c}{ CPB support } & \\
\cline { 2 - 3 } \multicolumn{1}{c}{ Risk factor } & Yes $(\mathbf{n}=\mathbf{2 7 1})$ & No $(\mathbf{n}=\mathbf{5 4})$ & P value \\
\hline Age $(\mathrm{d})$ & $202(78-1194)$ & $16.5(8-139.7)$ & $<.001$ \\
Weight $(\mathrm{kg})$ & $6.8(4.5-13.7)$ & $3.4(2.8-5.4)$ & $<.001$ \\
Gender & & & \\
$\quad$ Male & $152(56)$ & $32(59)$ & .88 \\
Female & $119(44)$ & $22(41)$ & .88 \\
Previous surgery (yes) & $95(35)$ & $4(7)$ & $<.001$ \\
Ventricle physiology & & & \\
Single & $74(27)$ & $16(30)$ & .74 \\
Two & $197(73)$ & $38(70)$ & .74 \\
RACHS-1 category & & & \\
1 & $22(8)$ & $9(17)$ & .07 \\
2 & $97(36)$ & $20(37)$ & .87 \\
3 & $77(29)$ & $20(37)$ & .25 \\
4 & $25(9)$ & $0(0)$ & .02 \\
$5-6$ & $33(12)$ & $0(0)$ & .002 \\
Unclassified & $17(6)$ & $5(9)$ & .02 \\
CPB time (min) & $120(88-158)$ & NA & - \\
Crossclamp time (min) & $41(24-58)$ & NA & - \\
Lowest temperature during & $29(27.2-30.9)$ & NA & - \\
CPB $\left({ }^{\circ} \mathrm{C}\right)$ & & & - \\
Lowest hematocrit during & $31(28-34)$ & NA & - \\
CPB & & & \\
Heparin dose (U/kg) & $414(400-559)$ & NA & - \\
Post-CPB temperature $\left({ }^{\circ} \mathrm{C}\right)$ & $35(34-36)$ & NA & - \\
\hline Do & & & \\
\hline
\end{tabular}

Data presented as median (interquartile range), with $P$ value determined using Wilcoxon rank sum test, or absolute number (\%), with $P$ value determined using chi-square or Fisher's exact test. CPB, Cardiopulmonary bypass; RACHS-1, Risk Adjusted Classification for Congenital Heart Surgery, version 1; NA, not applicable.

of adrenal insufficiency, 12 of $19(63 \%)$ complications of bacteremia/suspected sepsis, and 3 of $5(60 \%)$ complications of necrotizing enterocolitis were associated with low cardiac output. Eighteen patients underwent reoperation during the period that included thrombosed shunts. These 18 patients had a greater number of cardiac and extracardiac complications $(4.68 \pm 2.45)$ than the patients who did not require reoperation $(2.06 \pm 1.53 ; P<.001)$.

The evidence from logistic regression analysis was insufficient to reveal differences in the incidence of cardiac or extracardiac complications between cardiac surgeries performed with and without CPB support after adjusting for age, gender, previous sternotomy, and RACHS-1 level (Table 3).

The point of occurrence of cardiac and extracardiac complications in the postoperative pediatric cardiac surgery patients who survived to hospital discharge is listed in Table 4. Of the 80 cardiac complications and 131 extracardiac complications, $69(86 \%)$ and $117(89 \%)$ occurred before extubation, respectively. The incidence of permanent pacemaker implantation and gastrointestinal and infectious complications was greater after extubation (Table 4).
TABLE 2. Multiorgan postoperative complications

\begin{tabular}{|c|c|c|}
\hline \multirow[b]{2}{*}{ Complication } & \multicolumn{2}{|c|}{ CPB support } \\
\hline & Yes $(n=271)$ & No $(\mathbf{n}=\mathbf{5 4})$ \\
\hline Cardiac, total & $111(40.9)$ & $11(20.3)$ \\
\hline Cardiopulmonary resuscitation & $16(5.9)$ & $4(7.4)$ \\
\hline Extracorporeal membrane oxygenation & $18(6.6)$ & $1(1.8)$ \\
\hline Reoperation & $14(5.1)$ & $4(7.4)$ \\
\hline Low cardiac output status & $58(21.4)$ & $2(3.7)$ \\
\hline Permanent pacemaker & $5(1.8)$ & $0(0)$ \\
\hline Extracardiac, total & $169(62.3)$ & $14(25.9)$ \\
\hline Neurologic, total & $13(4.8)$ & $2(3.7)$ \\
\hline Seizures/focal deficit & $6(2.2)$ & $1(1.8)$ \\
\hline Abnormal neuroimaging findings & $7(2.6)$ & $1(1.8)$ \\
\hline Respiratory, total & $30(11)$ & $2(3.7)$ \\
\hline Use of inhaled nitric oxide & $26(9.5)$ & $1(1.8)$ \\
\hline Paralyzed diaphragm & $4(1.5)$ & $1(1.8)$ \\
\hline Gastrointestinal, total & $5(1.8)$ & $1(1.8)$ \\
\hline NEC & $4(1.5)$ & $1(1.8)$ \\
\hline Liver dysfunction & $1(0.4)$ & $0(0)$ \\
\hline Renal, total & $33(12.2)$ & $4(7.4)$ \\
\hline $\begin{array}{l}\text { Acute renal failure (not requiring } \\
\text { replacement therapy) }\end{array}$ & $13(4.8)$ & $2(3.7)$ \\
\hline Renal replacement therapy & $8(2.9)$ & $0(0)$ \\
\hline $\begin{array}{l}\text { Peritoneal dialysis catheter } \\
\text { placement }\end{array}$ & $13(4.8)$ & $2(3.7)$ \\
\hline Infectious, total & $23(8.5)$ & $4(7.4)$ \\
\hline Pneumonia & $1(0.4)$ & $0(0)$ \\
\hline Sternal wound infection & $6(2.2)$ & $1(1.8)$ \\
\hline Suspected sepsis/bacteremia & $16(5.9)$ & $3(5.5)$ \\
\hline Endocrine, total & $43(15.8)$ & $2(3.7)$ \\
\hline Hyperglycemia & $38(14)$ & $1(1.8)$ \\
\hline Adrenal insufficiency & $5(1.8)$ & $0(0)$ \\
\hline Hematologic & $22(8.1)$ & $1(1.8)$ \\
\hline $\begin{array}{l}\text { Bleeding requiring chest } \\
\text { re-exploration }\end{array}$ & $22(8.1)$ & $1(1.8)$ \\
\hline \multicolumn{3}{|l|}{ Cardiac complications/patient } \\
\hline 0 & $200(73)$ & $43(80)$ \\
\hline 1 & 45 (17) & $11(20)$ \\
\hline$>1$ & $26(10)$ & $0(0)$ \\
\hline \multicolumn{3}{|l|}{ Extracardiac complications/patient } \\
\hline 0 & $163(60)$ & $42(78)$ \\
\hline 1 & $72(27)$ & $11(20)$ \\
\hline$>1$ & $36(13)$ & $1(2)$ \\
\hline \multicolumn{3}{|l|}{ Total complications/patient } \\
\hline 0 & $150(55)$ & $49(91)$ \\
\hline 2 & $57(21)$ & $4(7)$ \\
\hline$>2$ & $64(11)$ & $1(2)$ \\
\hline
\end{tabular}

Data presented as absolute number (\%). $C P B$, Cardiopulmonary bypass.

For the 271 cardiac surgeries performed with $\mathrm{CPB}$, the results of the evaluation of risk factors for the number of cardiac and extracardiac complications are listed in Table 5. Proportional odds logistic regression analysis revealed that a longer CPB time, higher RACHS-1 level, and lower temperature during CPB were significantly associated with a greater number of cardiac complications and that a longer CPB time and higher RACHS-1 level were significantly 
TABLE 3. Logistic regression analysis of complications and outcomes

\begin{tabular}{|c|c|c|c|c|c|}
\hline \multirow[b]{2}{*}{ Outcome } & \multicolumn{2}{|c|}{ CPB support } & \multirow[b]{2}{*}{ OR } & \multirow[b]{2}{*}{$95 \% \mathrm{CI}$} & \multirow[b]{2}{*}{$P$ value* } \\
\hline & Yes $(n=271)$ & No $(n=54)$ & & & \\
\hline Cardiac complications & $71(26)$ & $11(20)$ & 0.83 & $0.33-1.94$ & .626 \\
\hline Extracardiac complications & $108(40)$ & $12(22)$ & 0.84 & $0.83-4.12$ & .135 \\
\hline
\end{tabular}

$\overline{C P B}$, Cardiopulmonary bypass; $O R$, odds ratio; $C I$, confidence interval. *Risk factors adjusted for logistic regression analysis included age, gender, previous surgery, and Risk Adjusted Classification for Congenital Heart Surgery, version 1, category.

associated with a greater number of extracardiac complications. No cardiac complications occurred in those with RACHS-1, category 1 . Thus, to compare the risk of cardiac complications across the RACHS-1 categories, applying each category as an ordinate variable, RACHS-1 categories 3, 4, and 5-6 were compared with RACHS-1 categories 1 and 2 together. For our analysis, only 1 multivariate logistic regression model was fitted, in which the factors were chosen a priori according to scientific and sample size considerations. Any association presented in Table 5 for a specific variable (eg, CPB time) and an outcome (eg, cardiac complications) was thus adjusted for all other factors listed.

The association of postoperative complications for CPB patients with the length of mechanical ventilation and PCICU stay is listed in Table 6. The presence of postoperative complications, prolonged CPB duration, lower hematocrit and lower temperature during $\mathrm{CPB}$, and younger age were significantly associated with prolonged mechanical ventilation. The presence of postoperative complications,

TABLE 4. Point of occurrence of cardiac and extracardiac postoperative complications and their relationship to extubation in pediatric cardiac surgery patients surviving to hospital discharge

\begin{tabular}{|c|c|c|c|}
\hline Complication & $\mathbf{n}$ & $\begin{array}{c}\text { Point of } \\
\text { occurrence (d) }\end{array}$ & $\begin{array}{c}\text { Complications } \\
\text { occurring before } \\
\text { extubation }\end{array}$ \\
\hline $\begin{array}{l}\text { Cardiopulmonary } \\
\text { resuscitation }\end{array}$ & 12 & $0(0-12)$ & $9(75)$ \\
\hline $\begin{array}{l}\text { Extracorporeal membrane } \\
\text { oxygenation }\end{array}$ & 5 & $0(0-7.3)$ & $5(100)$ \\
\hline Reoperation & 12 & $10(6.5-23.5)$ & $9(75)$ \\
\hline Low cardiac output status & 46 & $0(0-0)$ & $46(100)$ \\
\hline Permanent pacemaker & 5 & $14(14-15)$ & $0(0)$ \\
\hline Neurologic, total & 9 & $3(2.5-6.5)$ & $7(78)$ \\
\hline Use of inhaled nitric oxide & 25 & $0(0-0)$ & $24(96)$ \\
\hline Paralyzed diaphragm & 4 & $21(12.7-33.5)$ & $4(100)$ \\
\hline Gastrointestinal, total & 4 & $21(15-24)$ & $1(25)$ \\
\hline Acute renal failure & 7 & $5(2-7)$ & $6(86)$ \\
\hline Renal replacement therapy & 2 & $3(2.3-10)$ & $2(100)$ \\
\hline $\begin{array}{l}\text { Peritoneal dialysis catheter } \\
\text { placement }\end{array}$ & 12 & $2(1-7)$ & $12(100)$ \\
\hline Infectious, total & 23 & $12(4.5-34.5)$ & $16(70)$ \\
\hline Endocrine, total & 29 & $0(0-0)$ & $29(100)$ \\
\hline $\begin{array}{l}\text { Bleeding requiring chest } \\
\text { re-exploration }\end{array}$ & 16 & $0(0-0)$ & $16(100)$ \\
\hline
\end{tabular}

higher RACHS-1 level, and prolonged CPB duration were significantly associated with a prolonged PCICU stay (Table 6), after adjustment for relevant covariates.

The association of postoperative complications for CPB patients with the length of hospital stay is listed in Table 7. The presence of postoperative complications was significantly associated with a prolonged hospital stay, after adjustment for relevant covariates.

For the 54 surgeries performed without CPB support, complications were significantly associated with prolonged mechanical ventilation $(45.42 \pm 27.21$ hours vs $17.85 \pm$ 18.16 hours; $P=.001$ ), a prolonged PCICU stay (11.67 \pm 12.26 days vs $3.17 \pm 4.38$ days; $P=.002$ ), and a prolonged hospital stay $(24.6 \pm 31.56$ days vs $7.56 \pm 8.43$ days; $P=.004)$ compared with no complications.

Postoperative complications had developed in all 22 patients who died in our study. The patients who died had a significantly greater number of complications $(4.1 \pm 2.0)$ than those who survived $(0.7 \pm 1.2 ; P<.001)$. Evaluation of the association of mortality with the individual complications revealed mortality in 12 of 19 patients $(63 \%)$ requiring extracorporeal membrane oxygenation support, 7 of $18(39 \%)$ requiring reoperation, 7 of $20(35 \%)$ requiring cardiopulmonary resuscitation, and 15 of 60 $(25 \%)$ with low cardiac output. Mortality was also observed in 13 of 24 patients $(54 \%)$ with acute renal failure with or without the need for renal replacement therapy, 9 of 39 $(23 \%)$ with hyperglycemia, and 5 of $27(18 \%)$ with infectious complications. Greater mortality was observed in those with combined cardiac and extracardiac complications (18 of 59 patients [30.5\%]) than those with either cardiac or extracardiac complications (4 of 79 patients [5\%]; $P<.001$ ).

For the 271 surgeries performed using $\mathrm{CPB}$, logistic regression analysis revealed that the RACHS-1 level was associated with mortality (odds ratio, 1.73 ; $95 \%$ CI, 1.22 $2.66 ; P=.013$ ). Also, the total number of cardiac and extracardiac complications was significantly associated with mortality (odds ratio, 2.10; 95\% CI, 1.52-2.91; $P<.001$ ). Likewise, for the 54 surgeries performed without CPB, the presence of complications in 15 patients was significantly associated with mortality compared with a lack of complications in 39 patients $(P=.018)$.

The association of postoperative complications with survival persisted beyond the hospital stay. Of the 184 patients without postoperative complications evaluated 1 year after 
TABLE 5. Evaluation of risk factors for patients undergoing cardiac surgery with cardiopulmonary bypass for cardiac and extracardiac complications

\begin{tabular}{|c|c|c|c|c|}
\hline \multirow[b]{2}{*}{ Risk factors } & \multicolumn{2}{|c|}{ Cardiac complications } & \multicolumn{2}{|c|}{ Extracardiac complications } \\
\hline & OR $(95 \%$ CI $)$ & $P$ value & OR $(95 \%$ CI $)$ & $P$ value \\
\hline Age (y) & $0.99(0.85-1.16)$ & .96 & $1.02(0.93-1.13)$ & .65 \\
\hline Gender (male vs female) & $1.18(0.51-2.73)$ & .69 & $1.23(0.65-2.34)$ & .53 \\
\hline Previous surgery (yes vs no) & $0.76(0.14-4.16)$ & .75 & $0.84(0.28-3.18)$ & .94 \\
\hline Single-ventricle physiology & $0.81(0.12-5.59)$ & .83 & $0.95(0.28-3.18)$ & .12 \\
\hline RACHS- 1 category & & $.02 *$ & & $.03 \dagger$ \\
\hline 2 & - & & $1.03(0.19-5.65)$ & \\
\hline 3 & $2.75(0.81-9.36)$ & & $2.69(0.45-15.95)$ & \\
\hline 4 & $6.54(1.78-24.04)$ & & $1.98(0.28-13.89)$ & \\
\hline $5-6$ & $10.16(1.11-93.24)$ & & $4.78(0.51-44.36)$ & \\
\hline CPB time (h) & $1.98(1.13-3.46)$ & .02 & $1.94(1.21-3.12)$ & .006 \\
\hline Crossclamp time (min) & $0.99(0.97-1.01)$ & .40 & $0.99(0.98-1.00)$ & .33 \\
\hline $\begin{array}{l}\text { Lowest temperature during } \\
\qquad \mathrm{CPB}\left({ }^{\circ} \mathrm{C}\right)\end{array}$ & $0.79(0.67-0.94)$ & .007 & $0.95(0.84-1.07)$ & .38 \\
\hline $\begin{array}{l}\text { Lowest hematocrit during } \\
\text { CPB }\end{array}$ & $1.09(0.99-1.21)$ & .06 & $1.07(0.98-1.15)$ & .10 \\
\hline Heparin $(\mathrm{U} / \mathrm{kg})$ & $0.99(0.93-1.00)$ & .27 & $0.99(0.79-1.25)$ & .21 \\
\hline Post-CPB temperature $\left({ }^{\circ} \mathrm{C}\right)$ & $0.99(0.93-1.07)$ & .93 & $0.99(0.98-1.00)$ & .96 \\
\hline
\end{tabular}

$P$ value determined from proportional odds logistic regression model. OR, Odds ratio; $C I$, confidence interval; RACHS-1, Risk Adjusted Classification for Congenital Heart Surgery, version $1 ; C P B$, cardiopulmonary bypass. ${ }^{*} P$ value determined by analyzing RACHS-1 levels as categorical variables comparing each category with RACHS-1 categories 1-2. $\dagger P$ value determined by analyzing RACHS-1 levels as categorical variables comparing each category with RACHS-1 category 1 .

cardiac surgery, data were missing for 32 patients $(17 \%)$, and none of the remaining 152 patients had died. Of the 141 patients with complications, 22 had died during their hospital stay. Of the 119 patients with postoperative complications who were discharged home, data were missing for 21 patients $(17 \%)$ and 4 patients had died within 1 year of follow-up. The difference in the number of deaths between patients with and without complications was statistically significant $(P=.028)$. Evaluation of the 98 patients with postoperative complications who were discharged home revealed that the 4 patients who subsequently died had had significantly more postoperative complications $(3.8 \pm 2.8)$ than the 96 patients who survived $(2.1 \pm 1.5$; $P=.036)$.

TABLE 6. Study of cardiopulmonary bypass parameters and complications with mechanical ventilation duration and pediatric intensive care unit stay

\begin{tabular}{|c|c|c|c|c|}
\hline \multirow[b]{2}{*}{ Risk factor } & \multicolumn{2}{|c|}{ Mechanical ventilation duration } & \multicolumn{2}{|c|}{ PCICU stay } \\
\hline & Ratio of geometric mean $(95 \% \mathrm{CI})$ & $P$ value* & OR $(95 \%$ CI $)$ & $P$ value \\
\hline Age (y) & $0.99(0.97-1.03)$ & .84 & $0.99(0.92-1.07)$ & .86 \\
\hline Gender (male vs female) & $1.02(0.83-1.26)$ & .84 & $1.28(0.75-2.2)$ & .36 \\
\hline Previous surgery (yes vs no) & $0.82(0.57-1.18)$ & .3 & $0.49(0.18-1.32)$ & .16 \\
\hline Single-ventricle physiology & $1.32(0.88-1.97)$ & .18 & $1.96(0.68-6.6)$ & .21 \\
\hline RACHS- 1 category & & $.24 \ddagger$ & & $.003 \ddagger$ \\
\hline 2 & $1.18(0.77-1.79)$ & & $1.98(0.59-6.59)$ & \\
\hline 3 & $1.75(1.09-2.82)$ & & $4.37(1.16-16.41)$ & \\
\hline 4 & $2.39(1.39-4.10)$ & & $12.47(2.70-57.14)$ & \\
\hline $5-6$ & $2.00(1.03-3.91)$ & & $6.94(1.17-41.2)$ & \\
\hline CPB time (h) & $1.11(0.94-1.31)$ & .20 & $2.16(1.41-3.32)$ & $<.001$ \\
\hline Crossclamp time (min) & $1.00(0.99-1.01)$ & .86 & $0.99(0.98-1.01)$ & .63 \\
\hline Lowest temperature during $\mathrm{CPB}\left({ }^{\circ} \mathrm{C}\right)$ & $0.97(0.94-1.01)$ & .13 & $0.94(0.86-1.03)$ & .19 \\
\hline Lowest hematocrit during $\mathrm{CPB}$ & $1.01(0.99-1.04)$ & .25 & $1.05(0.98-1.11)$ & .15 \\
\hline Heparin $(\mathrm{U} / \mathrm{kg})$ & $1.00(0.99-1.00)$ & .48 & $1.00(0.99-1.00)$ & .91 \\
\hline Post-CPB temperature $\left({ }^{\circ} \mathrm{C}\right)$ & $1.00(0.99-1.00)$ & .83 & $1.00(0.99-1.00)$ & .63 \\
\hline Complications (yes vs no) & $1.38(1.10-1.74)$ & .006 & $2.51(1.41-4.45)$ & .002 \\
\hline
\end{tabular}

$P C I C U$, Pediatric cardiac intensive care unit; $C I$, confidence interval; $O R$, odds ratio; RACHS-1, Risk Adjusted Classification for Congenital Heart Surgery, version 1; $C P B$, cardiopulmonary bypass. $* P$ value determined using linear regression analysis. $\dagger P$ value determined using proportional odds logistic regression analysis. $\ddagger P$ value determined according to RACHS-1 levels analyzed as categorical variables comparing each category with RACHS-1 category 1. 
TABLE 7. Study of cardiopulmonary bypass parameters and complications with length of hospital stay

\begin{tabular}{|c|c|c|}
\hline \multirow[b]{2}{*}{ Risk factor } & \multicolumn{2}{|c|}{ Length of hospital stay } \\
\hline & $\begin{array}{c}\text { Ratio of geometric } \\
\text { mean }(95 \% \mathrm{CI})\end{array}$ & $P$ value* \\
\hline Age $(y)$ & $0.99(0.97-1.03)$ & .20 \\
\hline Gender (male vs female) & $1.02(0.83-1.26)$ & .84 \\
\hline Previous surgery (yes vs no) & $0.77(0.52-1.13)$ & .18 \\
\hline Single-ventricle physiology & $1.32(0.88-1.97)$ & .18 \\
\hline RACHS- 1 category & & $.24 \dagger$ \\
\hline 2 & $1.18(0.77-1.79)$ & \\
\hline 3 & $1.75(1.09-2.82)$ & \\
\hline 4 & $2.39(1.39-4.11)$ & \\
\hline $5-6$ & $2.00(1.03-3.91)$ & \\
\hline CPB time $(\mathrm{h})$ & $1.11(0.94-1.31)$ & .20 \\
\hline Crossclamp time (min) & $1.00(0.99-1.00)$ & .86 \\
\hline Lowest temperature during $\mathrm{CPB}\left({ }^{\circ} \mathrm{C}\right)$ & $0.97(0.94-1.01)$ & .13 \\
\hline Lowest hematocrit during $\mathrm{CPB}$ & $1.01(0.99-1.04)$ & .25 \\
\hline Heparin $(\mathrm{U} / \mathrm{kg})$ & $1.00(0.99-1.00)$ & .48 \\
\hline Post-CPB temperature $\left({ }^{\circ} \mathrm{C}\right)$ & $1.00(0.99-1.00)$ & .83 \\
\hline Complications (yes vs no) & $1.38(1.10-1.74)$ & .006 \\
\hline $\begin{array}{l}C I \text {, Confidence interval; } R A C H S-1, R A C \\
\text { Congenital Heart Surgery, version } 1 ; C P B, \\
\text { mined using linear regression analysis. } \dagger P \\
\text { levels analyzed as categorical variables c } \\
\text { category } 1 \text {. }\end{array}$ & $\begin{array}{l}-1 \text {, Risk Adjusted } \mathrm{Cl} \\
\text { diopulmonary bypass. }\end{array}$ & $\begin{array}{l}\text { fication for } \\
\text { value deter- } \\
\text { RACHS-1 } \\
\text { RACHS-1 }\end{array}$ \\
\hline
\end{tabular}

\section{DISCUSSION}

Our data have demonstrated that postoperative cardiac and extracardiac complications occurred in $43 \%$ of pediatric cardiac surgery patients. Postoperative complications occurred in surgeries performed both with and without $\mathrm{CPB}$ support. For those performed with $\mathrm{CPB}$, a longer $\mathrm{CPB}$ duration was significantly associated with an increased number of cardiac and extracardiac complications. Postoperative complications were significantly associated with other established outcome measures, including the duration of mechanical ventilation, length of PCICU stay, length of hospital stay, and mortality.

Our study revealed a greater incidence of extracardiac complications compared with cardiac complications. The complication rate we observed was greater than the previously reported rates of $33 \%$ to $39 \%$ in pediatric patients and $29 \%$ in neonatal patients. ${ }^{4-6}$ The greater complication rate observed in our study might have resulted from a more inclusive method of data collection. We used simple and unequivocal criteria to define each complication..$^{10,11}$ Complications were derived from the clinical charts after manually reviewing multiple data observations, including physician notes, nurse records, radiologic and laboratory results, and hemodynamic monitoring points. Previous reports on the incidence of postoperative complications have been assessed from administrative and clinical databases. $^{4-6}$ An administrative database study by Benavidez and colleagues ${ }^{4}$ applied the "International
Classification of Diseases, 9th Revision, Clinical Modification," to define the complications and reported that one third of pediatric cardiac surgery patients had complications. Administrative data provide limited clinical information and have problems in coding accuracy, variation, and limited insight into the timing and severity of events. ${ }^{13}$ Codes cannot reliably distinguish between comorbidities and procedural complications. ${ }^{13}$ Administrative databases have wide discrepancy with clinical databases in the reporting of cases, mortality, and diagnoses. ${ }^{14}$ Clinical databases, although more accurate in anatomic and operative detail, vary from institution to institution in the degree of capture of complications. ${ }^{15,16}$ A clinical database study by Pasquali and colleagues ${ }^{5}$ applied Society of Thoracic Surgeons Congenital Heart Surgery database definitions and reported a complication rate of $39 \%$. Comparisons of the clinical data with the Society of Thoracic Surgeons National Cardiac database have shown discrepancies of $6 \%$ for composite major morbidity/mortality and 36\% for ventilation time. ${ }^{15}$ A comparison of the Society of Thoracic Surgeons Congenital Heart Surgery database records with clinical data revealed a lack of agreement of $40 \%$ for the initial extubation date and time, $38 \%$ for 30 -day mortality status, and $29 \%$ for postoperative complications. ${ }^{16}$ The discrepancy in complications resulted predominantly from underreporting. ${ }^{16}$

We observed that postoperative complications occurred in cardiac surgeries performed both with and without CPB. Our observations differed from previous study results, which reported an increase in postoperative complications in pediatric cardiac surgery undertaken with CPB compared with no CPB. ${ }^{6}$ The variance in observations between the 2 studies might have resulted from differences in the study populations and the analysis undertaken. Kansy and colleagues ${ }^{6}$ studied neonatal cardiac surgery patients and reported an increase in complications with CPB use from the univariate analysis. Increased complexities of cardiac defects, including RACHS-1 level category 5 and 6, which are associated with a greater incidence of postoperative complications, will be performed in the neonatal period. ${ }^{4}$ Our study population included all age groups (0-18 years), with the exclusion of neonatal patent ductus arteriosus ligation and surgical patients admitted directly to the pediatric cardiology floor for postoperative care. Our analysis of the number of complications was adjusted for multiple parameters, including age, gender, previous sternotomy, and RACHS-1 level. For cardiac surgery performed with CPB, our study observations revealed that an increased duration of CPB and increased cardiac defect complexity were significant risk factors for an increased number of cardiac and extracardiac complications. These observations are partly in agreement with those from previous studies., ${ }^{4,6}$ Additional support for an association of the CPB duration with the occurrence of complications includes a 
dose-dependent elevation of circulating inflammatory mediators and cytokines with the duration of CPB. ${ }^{17,18}$

Our study observations revealed that postoperative complications after CPB use were significantly associated with other measured outcomes, including the duration of mechanical ventilation, length of intensive care unit and hospital stay, and mortality, after adjustment for relevant confounders. Our results are partly in agreement with those from adult cardiac surgery studies that have reported that postoperative complications were significantly associated with a prolonged hospital stay. ${ }^{19,20}$ A general tendency exists to optimize the patient's vital parameters and ensure multiorgan system stability before a pediatric cardiac surgery patient is extubated and subsequently transferred to the pediatric cardiology floor. Of the complications in our study population, $86 \%$ of cardiac and $89 \%$ of extracardiac complications occurred before extubation. Thus, the presence of any postoperative complication would delay extubation and transfer to the pediatric cardiology floor. The association of postoperative complications with worse outcomes in our study persisted beyond the perioperative period, with a prolonged hospital stay and decreased rate of survival 1 year after cardiac surgery. The association of postoperative complications with mortality is consistent with the findings of previous studies. ${ }^{4,5}$

The present single-center retrospective study was limited by the subjectivity of defining and counting the complications and the limited ability to generalize the findings meaningfully to other institutions with different systems. Second, we did not assess whether the postoperative complications were a complication of a specific surgical intervention. Of the 20 patients in our study who developed postoperative acute renal failure, 2 had had preoperative renal dysfunction, and 8 of the 30 patients who had received inhaled nitric oxide postoperatively had pre-existent elevated pulmonary vascular resistance or elevated pulmonary artery pressure. None of the patients who had developed neurologic complications were known to have had them before surgery, and none of the patients who developed necrotizing enterocolitis had been premature. All the neonatal patients underwent head and renal ultrasonography before surgery to rule out major structural abnormalities. Third, because of our study design was retrospective, human factors, including surgical practices, difficulties during surgery, variations in CPB techniques, and the management practices of the different anesthesia and cardiac critical teams, could not be evaluated. Fourth, we used the RACHS-1 level to evaluate the complexity of the cardiac defect. Better models might be available to comprehensively evaluate the complexity of the cardiac defect. However, in our study of 325 patients, only 22 patients $(7 \%)$ were in the unclassified category of RACHS- 1 level. Most of these patients $(n=15)$ underwent surgery without $\mathrm{CPB}$ use and did not develop any postoperative complications. Fifth, we were not able to determine which specific complication was associated with worse outcomes. Sixth, the correlation of complications to an untoward outcome in the "failure to rescue" principle might not extrapolate to all institutions. ${ }^{5}$ Identifying and correcting complications early might change the relationship of complication development and mortality; thus, the downstream effects of a given complication might differ from 1 institution to the next, depending on the infrastructure. The associations between complications and outcome might be most important in establishing patterns to target early recognition and preventive treatment. Finally, given the retrospective nature of our analysis, the correlation between postoperative complications and other measured outcomes could not prove causality.

Despite these limitations, our study has shown that postoperative cardiac and extracardiac complications affect a large proportion of patients, and the consequences are important to the length of the hospital course, cost, and outcome. The greater rate of complications may allow for better discrimination of outcomes among hospitals. A systematic and accurate analysis of complications could inform strategies better than the currently used standard criteria of mortality, mechanical ventilation duration, and length of hospital stay. Postoperative cardiac and extracardiac complications will occur with pediatric cardiac surgery, regardless of the use of CPB. We have reported a significant association of postoperative complications with currently measured outcomes, including mechanical ventilation duration, length of intensive care unit stay, length of hospital stay, and mortality. The association of postoperative complications with reduced survival can persist beyond hospital discharge. Additional studies are needed to evaluate cardiac and extracardiac postoperative complications as a valid measure of outcomes comparable among pediatric heart programs.

We would like to thank Meng Xu, MS, Department of Biostatistics, Vanderbilt University Medical Center, for her assistance with statistical analysis of our project.

\section{References}

1. Jacobs JP, Lacour-Gayet FG, Jacobs ML, Clarke DR, Tchervenkov CI, Gaynor JW, et al. Initial application in the STS congenital database of complexity adjustment to evaluate surgical case mix and results. Ann Thorac Surg. 2005; 79: 1635-49.

2. European Association for Cardiothoracic Surgery Congenital Database. Available at: www.eactscongenitaldb.org. Accessed January 23, 2013.

3. Jacobs JP, Mavroudis C, Jacobs ML, Maruszewski B, Tchervenkov CI, LacourGayet FG, et al. What is operative mortality? Defining death in a surgical registry database: a report of the STS Congenital Database Taskforce and the Joint EACTS-STS Congenital Database Committee. Ann Thorac Surg. 2006;81: 1937-41.

4. Benavidez OJ, Gauvreau K, Del Nido P, Bacha E, Jenkins KJ. Complications and risk factors for mortality during congenital heart surgery admissions. Ann Thorad Surg. 2007;84:147-55.

5. Pasquali SK, He X, Jacobs JP, Jacobs ML, O'Brien SM, Gaynor JM. Evaluation of failure to rescue as a quality metric in pediatric heart surgery: an 
analysis of the STS Congenital Heart Surgery Database. Ann Thorac Surg. 2012;94:573-80

6. Kansy A, Tobota Z, Maruszewski P, Maruszewski B. Analysis of 14,843 neonatal congenital heart surgical procedures in the European Association for Cardiothoracic Surgery Congenital Database. Ann Thorac Surg. 2010;89:1255-9.

7. Centers for Medicare and Medicaid Services. Hospital-acquired conditions (present on admission indicator). Available at: www.cms.gov/HospitalAcqCond/. Accessed February 26, 2013.

8. O'Brien SM, Jacobs JP, Clarke DR, Maruszewski B, Jacobs ML, Walters HL III, et al. Accuracy of the Aristotle basic complexity score for classifying the mortality and morbidity potential of congenital heart surgery operations. Ann Thorac Surg. 2007;84:2027-37.

9. Clarke DR, Lacour-Gayet F, Jacobs JP, Jacobs ML, Maruszewski B, Pizarro C, et al. The assessment of complexity in congenital cardiac surgery based on objective data. Cardiol Young. 2008;18(Suppl 2):169-76.

10. [No authors listed]. Part IV - the dictionary of definitions of complications associated with the treatment of patients with congenital cardiac disease. Cardiol Young. 2000;18(Suppl 2):282-530.

11. Walsh MC, Kliegman RM. Necrotizing enterocolitis: treatment based on staging criteria. Pediatr Clin North Am. 1986;33:179-201.

12. Jenkins KJ. Risk adjustment for congenital heart surgery: the RACHS-1 method. Semin Thorac Cardiovasc Surg Pediatr Card Surg Annu. 2004;7:180-4.

13. Torchiana DF, Meyer GS. Use of administrative data for clinical quality measurement. J Thorac Cardiovasc Surg. 2005;129:1223-5.
14. Mack MJ, Herbert M, Prince S, Dewey TM, Magee MJ, Edgerton JR. Does reporting of coronary artery bypass grafting from administrative databases accurately reflect actual clinical outcomes? J Thorac Cardiovasc Surg. 2005;129: 1309-17.

15. Herbert MA, Prince SL, Williams JL, Magee MJ, Mack MJ. Are unaudited records from an outcomes registry database accurate? Ann Thorac Surg. 2004; 77:1960-4.

16. Clarke DR, Breen LS, Jacobs ML, Franklin RCG, Tobota Z, Maruszewski B, et al. Verification of data in congenital cardiac surgery. Cardiol Young. 2008; 18(Suppl 2):177-87.

17. Allan CK, Newburger JW, McGrath E, Elder J, Psoinos C, Laussen PC, et al. The relationship between inflammatory activation and clinical outcome after infant cardiopulmonary bypass. Anesth Analg. 2010;111:1244-51.

18. Khabar KS, elBarbary MA, Khouqeer F, Devol E, al-Gain S, al-Halees Z. Circulating endotoxin and cytokines after cardiopulmonary bypass: differential correlation with duration of bypass and systemic inflammatory response/multiple organ dysfunction syndromes. Clin Immunol Immunopath. 1997;85:97-103.

19. Lazar HL, Fitzgerald C, Gross S, Heeren T, Aldea GS, Shemin RJ. Determinants of length of stay after coronary artery bypass graft surgery. Circulation. 1995; 92(9 Suppl):II20-4.

20. Welsby IJ, Bennett-Guerrero E, Atwell D, White WD, Newman MF, Smith PK, et al. The association of complication type with mortality and prolonged stay after cardiac surgery with cardiopulmonary bypass. Anesth Analg. 2002;94: $1072-8$. 


\begin{tabular}{lc}
\hline \multicolumn{1}{c}{ Complication } & Definition \\
\hline Cardiac & Cessation of effective cardiac mechanical function necessitating cardiopulmonary resuscitation \\
Cardiac arrest & Need for ECMO coming off CPB or need for ECMO during operative period, including need for ECMO as \\
$\begin{array}{l}\text { Extracorporeal life support (ECMO) } \\
\text { in postoperative period }\end{array}$ & part of cardiopulmonary resuscitation \\
Reoperation & Unplanned cardiac operation during same admission \\
Low cardiac output & Low cardiac output state, characterized by use of $\geq 3$ inotropes and associated with the following: \\
& tachycardia, oliguria, decreased skin perfusion, metabolic acidosis, or vasopressin requirement for \\
& hypotension and/or shock in postoperative period \\
Use of pacemaker, permanent & Persistent rhythm problem necessitating placement of permanent pacemaker
\end{tabular}

Noncardiac

Neurologic

Seizures or focal neurologic deficit

Abnormal neuroimaging findings

Respiratory

Use of inhaled nitric oxide

Paralyzed diaphragm (requiring surgical intervention)

Gastrointestinal

Necrotizing enterocolitis

Liver dysfunction

Renal complications

Acute renal dysfunction

Renal replacement therapy

Peritoneal drain catheter placement (ascites, requiring drainage)

Infectious

Pneumonia

Sternal wound infection

Suspected infection/bacteremia

\author{
Endocrine \\ Hyperglycemia \\ Adrenal insufficiency
}

Hematologic
Cessation of effective cardiac mechanical function necessitating cardiopulmonary resuscitation eed for ECMO coming off CPB or need for ECMO during operative period, including need for ECMO as part of cardiopulmonary resuscitation

Unplanned cardiac operation during same admission

Low cardiac output state, characterized by use of $\geq 3$ inotopes and associated with the following: hypotension and/or shock in postoperative period

Persistent rhythm problem necessitating placement of permanent pacemaker

New-onset seizures or new-onset focal neurologic changes

Head ultrasound/brain CT scan/brain MRI showing evidence of ischemic or hemorrhagic changes-suspected to be of recent onset

Indirect evidence of pulmonary hypertension (clinically significant elevation of pulmonary arterial pressure requiring intervention)

Evidence of weak, immobile, or paradoxical movement assessed by ultrasound or fluoroscopy

Suspected: feeding intolerance with abdominal distension, dilated bowel loops on radiograph and hematochezia; diagnosed: persistent dilated loops on radiograph (fixed bowel loop pattern) and/or perforation, along with feeding intolerance, abdominal distension, and hematochezia

Elevation of hepatic enzymes (ALT and AST $\geq 100 \mathrm{U} / \mathrm{L}$ )

Transient azotemia: elevated BUN and creatinine $>1.5$ times upper limit of normal for age (or twice the most recent values)

Acute renal failure with new requirement for temporary dialysis, including peritoneal dialysis or hemodialysis or CVVH

Accumulation of fluid in peritoneal cavity requiring peritoneal drain placement

Fever, elevated WBC count, new infiltrate on chest radiograph, and positive endotracheal tube culture; ventilator-associated pneumonia included

Including both superficial and deep sternal wound infections-superficial: purulent discharge from superficial portion of incision; organisms isolated from aseptically obtained culture of fluid or tissue from superficial portion of incision; tenderness and/or redness; deep: purulent drainage from deep portions of incision; deep incision spontaneously dehisces or deliberately opened by surgeon; symptoms of fever, localized tenderness, abscess, or other evidence of infection involving deep incision found on direct examination

Clinical manifestations of infection (fever/elevated WBC count and/or elevated CRP) and no apparent source of infection (culture negative)

Random blood glucose level $>200 \mathrm{mg} / \mathrm{dL}$ necessitating insulin infusion

Abnormal basal cortisol and ACTH stimulation test necessitating use of stress dose steroids (including both absolute and relative adrenal insufficiency)

Postoperative or postprocedural bleeding requiring reoperation

$\overline{E C M O}$, Extracorporeal membrane oxygenation; $C P B$, cardiopulmonary bypass; $C T$, computed tomography; $M R I$, magnetic resonance imaging; $A L T$, alanine aminotransferase; $A S T$, aspartate aminotransferase; $B U N$, blood urea nitrogen; $C V V H$, continuous venovenous hemofiltration; $W B C$, white blood cell; $C R P$, C-reactive protein; $A C T H$, adrenocorticotropic hormone. Data from [No authors listed]. Part IV—dictionary of definitions of complications associated with treatment of patients with congenital cardiac disease. Cardiol Young. 2008;18(Suppl S2):282-530 and from Walsh MC, Kliegman RM. Necrotizing enterocolitis: treatment based on staging criteria. Pediatr Clin North Am. 1986;33:179-201. 